\title{
The Role of Double-balloon Enteroscopy in the Diagnosis and Surgical Treatment of Metastatic Small Bowel Tumors
}

\author{
Naoyuki Nishimura, Motowo Mizuno, Yuichi Shimodate, Akira Doi, Hirokazu Mouri, \\ Kazuhiro Matsueda and Hiroshi Yamamoto
}

\begin{abstract}
:
Objective The aim of the present study is to investigate the role of double-balloon enteroscopy in the diagnosis and surgical treatment of metastatic small bowel tumors.

Patients We retrospectively reviewed the records of 13 patients with metastatic small bowel tumors among 376 patients who underwent double-balloon enteroscopy from June 2005 to March 2017 in our hospital.

Results The primary lesion sites were the lung $(n=9)$, kidney $(n=2)$, stomach $(n=1)$ and duodenum $(n=1)$. The clinical presentations were anemia requiring blood transfusion $(n=10)$, obstructive symptoms $(n=2)$, and no symptoms $(n=1)$. The locations of the metastatic small bowel tumors were the jejunum $(n=7)$, ileum $(n=$ $1)$, and both sites $(n=5)$. The histological diagnosis of the metastatic tumor was made from biopsy specimens taken with double-balloon enteroscopy from all 11 patients whose condition permitted a biopsy. In seven patients, the findings on double-balloon endoscopy were determinants of the kind and extent of surgical treatment performed. Four patients had multiple metastatic small bowel tumors, and all were able to be removed surgically with guidance from preoperative tattooing at double-balloon endoscopy. After operation, blood transfusions were no longer needed in four of six patients who had required preoperative transfusions for the treatment of anemia, and one patient with intestinal obstructive symptoms was able to resume oral intake.

Conclusion Double-balloon endoscopy was useful for making a histological diagnosis and directing surgical treatment in patients with metastatic small bowel tumors. Surgical treatment afforded palliation of symptoms in five patients.
\end{abstract}

Key words: double-balloon enteroscopy, small bowel tumors, small bowel metastases, surgery

(Intern Med 57: 1209-1212, 2018)

(DOI: 10.2169/internalmedicine.9877-17)

\section{Introduction}

Small bowel tumors (SBTs) have been considered rare, with an incidence of 1-2\% among all malignant gastrointestinal tumors (1). However, with the advent of video capsule endoscopy (VCE) and double-balloon enteroscopy (DBE), the detection rate has increased, and the recognized incidence accordingly has increased to $4 \%$ to $9 \%(2,3)$. Adenocarcinoma, malignant lymphoma, neuroendocrine tumor, and gastrointestinal stromal tumor are the most frequently reported SBTs (4-6); metastatic SBTs are rarer. The tumors may not cause symptoms, but they sometimes cause bleeding, obstruction, and bowel perforation (7-9). Because the prognosis of patients with metastatic SBTs usually is poor, their adequate examination and management is challenging. Studies on DBE or surgical treatment in metastatic SBT have not yielded sufficient data to permit reliable conclusions on the diagnosis and outcome of SBTs with advanced methods $(8,9)$.

In this study, we focused on metastatic SBT detected by $\mathrm{DBE}$ and investigated the role of DBE in the diagnosis and treatment of SBTs.

\section{Materials and Methods}

We retrospectively reviewed the endoscopic database and the electronic medical records of 570 DBEs performed in 
Table 1. Clinical Characteristics of the Patients, Findings of Double-balloon Enteroscopy and Treatment.

\begin{tabular}{|c|c|c|c|c|c|c|c|}
\hline case & age/sex & $\begin{array}{l}\text { primary cancer } \\
\text { site }\end{array}$ & $\begin{array}{l}\text { clinical } \\
\text { presentation }\end{array}$ & $\begin{array}{l}\text { metastasis of } \\
\text { small bowel }\end{array}$ & $\begin{array}{l}\text { number of } \\
\text { metastasis }\end{array}$ & treatment & $\begin{array}{l}\text { survival } \\
\text { (weeks) }\end{array}$ \\
\hline 1 & $60 / \mathrm{m}$ & kidney & blood loss & $\begin{array}{l}\text { jejunum and } \\
\text { ileum }\end{array}$ & multiple & $\begin{array}{l}\text { partial resection } \\
\text { and chemotherapy }\end{array}$ & 94 \\
\hline 2 & $75 / f$ & kidney & blood loss & jejunum & multiple & $\begin{array}{l}\text { partial resection } \\
\text { and chemotherapy }\end{array}$ & 51 \\
\hline 3 & $78 / \mathrm{m}$ & duodenum & blood loss & $\begin{array}{l}\text { jejunum and } \\
\text { ileum }\end{array}$ & multiple & $\begin{array}{l}\text { partial resection } \\
\text { and chemotherapy }\end{array}$ & 91 \\
\hline 4 & $72 / \mathrm{m}$ & stomach & stenosis & ileum & single & $\begin{array}{l}\text { partial resection } \\
\text { and chemotherapy }\end{array}$ & 13 \\
\hline 5 & $71 / \mathrm{m}$ & lung & blood loss & jejunum & single & $\begin{array}{l}\text { partial resection } \\
\text { and chemotherapy }\end{array}$ & 11 \\
\hline 6 & $49 / \mathrm{m}$ & lung & blood loss & $\begin{array}{l}\text { jejunum and } \\
\text { ileum }\end{array}$ & multiple & $\begin{array}{l}\text { partial resection } \\
\text { and chemotherapy }\end{array}$ & 7 \\
\hline 7 & $67 / f$ & lung & blood loss & jejunum & single & $\begin{array}{l}\text { partial resection } \\
\text { and chemotherapy }\end{array}$ & 12(alive) \\
\hline 8 & $71 / \mathrm{m}$ & lung & stenosis & jejunum & single & $\begin{array}{l}\text { conservative } \\
\text { therapy }\end{array}$ & 3 \\
\hline 9 & $59 / \mathrm{m}$ & lung & blood loss & jejunum & multiple & $\begin{array}{l}\text { conservative } \\
\text { therapy }\end{array}$ & 3 \\
\hline 10 & $80 / \mathrm{m}$ & lung & blood loss & jejunum & single & $\begin{array}{l}\text { conservative } \\
\text { therapy }\end{array}$ & 11 \\
\hline 11 & $74 / \mathrm{m}$ & lung & asymptomatic & jejunum & single & chemotherapy & 19 \\
\hline 12 & $75 / \mathrm{m}$ & lung & blood loss & $\begin{array}{l}\text { jejunum and } \\
\text { ileum }\end{array}$ & multiple & $\begin{array}{l}\text { conservative } \\
\text { therapy }\end{array}$ & 4 \\
\hline 13 & $71 / \mathrm{m}$ & lung & blood loss & $\begin{array}{l}\text { jejunum and } \\
\text { ileum }\end{array}$ & multiple & chemotherapy & 13 \\
\hline
\end{tabular}

376 patients at Kurashiki Central Hospital from June 2005 to March 2017. Thirteen patients who had metastatic SBTs were enrolled for this study. The study was approved by the institutional review board of the Kurashiki Central Hospital. Patients who had direct invasion from the primary cancer site or from metastatic abdominal lymph nodes to the small bowel, or had malignant lymphoma were excluded. Data of clinicopathological characteristics, time from the diagnosis of the primary cancer site, findings and complication of DBE, treatment after the diagnosis of the metastatic SBT, and the prognosis were collected.

DBE was performed with EN-450 P5 or EN-450 T5 (FUJIFILM, Tokyo, Japan). An oral or anal route for the DBE was chosen on the basis of the location of the suspected SBT, clinical presentation, and previous imaging studies. All procedures were performed with $\mathrm{CO}_{2}$ gas insufflation and moderate sedation. To aid in the identification of tumors at operation, the SBTs were tattooed via India ink injection during DBE. All patients gave their written informed consent before they underwent DBE.

The study was approved by the hospital's ethics committee. Statistical analyses were performed with the Statistical Package for Social Science, version 23 for Windows (SPSS, Chicago, USA).

\section{Results}

The clinical characteristics of the 13 patients with metas- tatic SBT are listed in Table 1. The mean age was 69 years, and 11 patients were men. The primary tumor sites were the lung $(n=9)$, kidney $(n=2)$, stomach $(n=1)$, and duodenum $(n=$ 1). The most common clinical presentations were symptoms related to blood loss (melena, $\mathrm{n}=7$ and anemia/occult gastrointestinal bleeding, $n=3$ ); all of these patients required blood transfusion before DBE. Another clinical presentation was intestinal obstructive symptoms (stenosis, $n=2$ ), and 1 patient was asymptomatic. The mean interval between the diagnosis of the primary cancer and the diagnosis of metastatic SBTs was 17 weeks (range 0-260 weeks). Cancer treatment given before the diagnosis of metastatic SBTs was surgery and chemotherapy $(n=5)$, chemotherapy only $(n=4)$, or surgery only $(n=1) ; 3$ patients received no anti-cancer therapy before the diagnosis was made.

Table 2 lists the diagnostic studies performed in the patients with suspected SBTs and the results. Computed tomography (CT) was performed in all 13 patients, and lesions suspected of being SBTs were identified in 9 (69\%). In the 4 patients with negative CT findings of SBTs, SBTs were suspected by VCE in two, fluoroscopic enteroclysis in one, and positron emission tomography with 2-deoxy-2[fluorine-18] fluoro-D-glucose integrated with computed tomography $\left({ }^{18} \mathrm{~F}-\mathrm{FDG}\right.$ PET/CT) in one. VCE was performed in four patients (two patients with negative and two with positive CT findings), and the test detected the SBT in all. The video capsule was retained in the small bowel of one patient who had no obstructive symptoms before VCE; the 
Table 2. Diagnostic Studies Performed on Patients with Suspected Metastatic SBT.

\begin{tabular}{|c|c|c|c|c|c|}
\hline Pt. no. & $\mathrm{CT}$ & VCE & $\begin{array}{l}\text { Fluoroscopic } \\
\text { enteroclysis }\end{array}$ & $\mathrm{PET} / \mathrm{CT}$ & DBE with biopsy* \\
\hline 1 & - & + & ND & ND & + \\
\hline 2 & + & ND & ND & ND & + \\
\hline 3 & + & ND & ND & ND & + \\
\hline 4 & - & + & ND & ND & + \\
\hline 5 & + & + & ND & ND & ND \\
\hline 6 & + & ND & ND & ND & ND \\
\hline 7 & + & ND & + & + & + \\
\hline 8 & + & ND & ND & ND & + \\
\hline 9 & + & ND & ND & ND & + \\
\hline 10 & + & ND & ND & ND & + \\
\hline 11 & - & ND & ND & + & + \\
\hline 12 & - & ND & + & ND & + \\
\hline 13 & + & + & + & + & + \\
\hline \multicolumn{6}{|c|}{$\begin{array}{l}\text { CT: computed tomography, VCE: video capsule endoscopy, PET/CT: positron } \\
\text { emission tomography with 2-deoxy-2-[fluorine-18] fluoro- D-glucose integrated } \\
\text { with computed tomography }\end{array}$} \\
\hline \multicolumn{6}{|c|}{ +: suspicious for SBT, -: negative for evidence of SBT, ND: not done } \\
\hline
\end{tabular}

capsule was retrieved with DBE.

DBE was performed via the oral route in nine patients, anal route in two, and both routes in two. The mean procedure time of DBE was 35 minutes (range 11-100 minutes). In all patients, at least one SBT was suspected based on findings from CT, VCE, fluoroscopic enteroclysis, and/or ${ }^{18}$ F-FDG PET/CT before DBE. DBE confirmed the metastatic SBTs, and biopsy specimens at DBE yielded a definite pathological diagnosis in all 11 patients whose condition permitted a biopsy. In addition, DBE detected unexpected SBTs that had not been recognized with any of other examinations in four patients. In two patients, metastatic SBTs were detected by DBE at the time of the diagnosis of the primary cancer. There were no recognized complications during or after DBE procedures.

Table 1 lists the small bowel sites of metastases, number of metastases, treatment of the malignancies, and survival time after the start of treatment. The small bowel sites of metastases were the jejunum $(n=7)$, jejunum and ileum $(n=$ $5)$, and ileum $(n=1)$. In six patients, a single small bowel metastasis was found; in seven patients, there were multiple metastases. Patients' treatment after the diagnosis of metastatic SBT was decided based on the findings of DBE, patients' general condition, and the expected prognosis. Among the 13 patients with metastatic SBTs, 7 (54\%) underwent surgical treatment followed by chemotherapy, 4 were managed with best supportive care, and the chemotherapy that had been started before the diagnosis of metastatic SBTs was continued in 2.

In cases 1 to 3 and 5 to 7 , surgical treatment was performed for the control of bleeding from metastatic SBTs. Further blood transfusion was averted in 4 of them after surgery, but blood transfusion was required in cases 1 and 3 due to bleeding from metachronous metastatic SBTs 92 and 64 weeks after surgery, respectively. In patients 1, 2, and 3, who had multiple metastatic SBTs, partial resection of two segments of the small bowel was performed, guided by the preoperative tattooing of the lesions at DBE, and all metastatic SBTs were able to be removed. In case 6, the metastatic SBTs were multiple and extensive, but one large tumor with bleeding identified on DBE was surgically resected, with control of bleeding. Small bowel stenosis was present in cases 4 and 8; resection of the lesion was performed in case 4 , and oral intake was possible at 6 weeks after surgery. No serious postoperative complications or perioperative deaths occurred.

In cases 8 to 11 , surgical treatment was not performed because of the patients' poor condition and short life expectancy. In cases 12 and 13, DBE revealed widely distributed metastatic SBTs in the small bowel. Among these without surgical treatment, continued blood transfusion was necessary in 4 cases $(9,10,12$, and 13) who had bleeding before DBE.

The mean overall survival period was 47 weeks in the patients who received surgical treatment and 8.8 weeks in those who did not receive surgical treatment.

\section{Discussion}

In this study, we assessed the value of DBE in making a diagnosis and surgically managing metastatic SBTs. Although CT, VCE, fluoroscopic enteroclysis, and PET are useful for making a diagnosis of metastatic SBT, only DBE enables a biopsy of lesions and thus a definitive diagnosis. In addition, DBE can identify SBTs undetected by other examinations and precisely localize tumors by tattooing so 
they can be readily identified during surgery. Multiple metastatic SBTs were detected in more than half of our patients; in some of these patients, all of the tumors were able to be removed at operation with the aid of preoperative tattooing with DBE. DBE may also be helpful in determining when surgical resection is an appropriate option abd the extent and type of operation advisable. Thus, although DBE is a more invasive examination than $\mathrm{CT}$ or VCE, it has several advantages.

In the evaluation of SBT, CT is often the initial examination, but its reported detection rate for SBTs smaller than 10 $\mathrm{mm}$ in size is low (17\%) and lower than that for VCE or DBE (8). In our study, CT identified probable metastatic SBT in $9 / 13(69 \%)$ of the 13 patients; VCE, fluoroscopic enteroclysis, or ${ }^{18} \mathrm{~F}$-FDG PET/CT detected SBTs in the other 4 patients who had negative CT findings. That the video capsule was retained in the small bowel of one patient is evidence of the risk associated with this procedure, even in the absence of bowel obstructive symptoms.

In our experience, DBE has been a safe procedure, and there were no adverse events in this study population. DBE has been reported to have a low rate of major adverse events, e.g. bowel perforation, bleeding, pancreatitis, and aspiration pneumonia (10). We have not found DBE to require a long time; the mean procedure time in this study was 35 minutes, which is shorter than that reported in another study (mean, 60 minutes) (11). Differences in indication for DBE might be relevant; we performed DBE only in patients suspected of having SBT with positive CT, VCE, fluoroscopic enteroclysis, and/or ${ }^{18} \mathrm{~F}-\mathrm{FDG}$ PET/CT findings. Thus, the results of the preceding examination made the search for SBTs easier and resulted in a shorter procedure time.

The prognosis and postoperative survival of patients with metastatic SBT are poor, as in this study, in which the mean overall survival period of the patients with and without surgical treatment was 47 and 8.8 weeks, respectively. However, this does not indicate the superiority of surgical treatment, because the patients in the two groups were not matched for clinical differences and similarities, and those selected for surgery generally had the longest life expectancy. Nevertheless, we feel that surgery palliated some patients' symptoms and gave the patients a chance to receive chemotherapy: after operation, blood transfusion was no longer needed in four of six patients, and oral intake became possible in one patient after surgery to relieve intestinal obstruction. The prognosis of patients whose primary cancer sites were not in the lung was relatively good following surgical treatment, whereas the prognosis of the patients with lung cancer was mostly poor. Thus, the primary cancer site of metastatic SMTs should also be taken into account regarding indications for DBE and surgical treatment.

Several limitations associated with the present study war- rant mention. First, this study had a small sample size, which reflects the rarity of metastatic SBT. Second, we were unable to evaluate the patients' quality of life objectively because of the retrospective nature of this review.

In conclusion, DBE is a useful and safe procedure for making a definitive diagnosis of metastatic SBTs. DBE can aid in the selection of the appropriate operation and, through the ability to tattoo lesions, help surgeons locate tumors for resection.

The authors state that they have no Conflict of Interest (COI).

\section{Acknowledgement}

The authors thank Dr. William R. Brown (Denver, Colorado) for his valuable assistance in the preparation of the manuscript.

\section{References}

1. Howe JR, Karnell LH, Menck HR, Scott-Conner C. The American College of Surgeons Commission on Cancer and the American Cancer Society. Adenocarcinoma of the small bowel: review of the National Cancer Data Base, 1985-1995. Cancer 86: 2693-2706, 1999.

2. Cobrin GM, Pittman RH, Lewis BS. Increased diagnostic yield of small bowel tumors with capsule endoscopy. Cancer 107: 22-27, 2006.

3. Cheung DY, Choi MG. Current advance in small bowel tumors. Clin Endosc 44: 13-21, 2011.

4. Mitsui K, Tanaka S, Yamamoto H, et al. Role of double-balloon endoscopy in the diagnosis of small-bowel tumors: the first Japanese multicenter study. Gastrointest Endosc 70: 498-504, 2009.

5. Fry LC, Neumann H, Kuester D, et al. Small bowel polyps and tumours: endoscopic detection and treatment by double-balloon enteroscopy. Aliment Pharmacol Ther 29: 135-142, 2009.

6. Cangemi DJ, Patel MK, Gomez V, Cangemi JR, Stark ME, Lukens FJ. Small bowel tumors discovered during double-balloon enteroscopy: analysis of a large prospectively collected singlecenter database. J Clin Gastroenterol 47: 769-772, 2013.

7. Gorski RL, Jalil SA, Razick M, Jalil AA. An obscure cause of gastrointestinal bleeding: renal cell carcinoma metastasis to the small bowel. Int J Surg Case Rep 15: 130-132, 2015.

8. Honda W, Ohmiya N, Hirooka Y, et al. Enteroscopic and radiologic diagnoses, treatment, and prognoses of small-bowel tumors. Gastrointest Endosc 76: 344-354, 2012.

9. Di JZ, Peng JY, Wang ZG. Prevalence, clinicopathological characteristics, treatment, and prognosis of intestinal metastasis of primary lung cancer: a comprehensive review. Surg Oncol 23: 72-80, 2014.

10. Xin L, Liao Z, Jiang YP, Li ZS. Indications, detectability, positive findings, total enteroscopy, and complications of diagnostic double-balloon endoscopy: a systematic review of data over the first decade of use. Gastrointest Endosc 74: 563-570, 2011.

11. Rahmi G, Samaha E, Vahedi K, et al. Multicenter comparison of double-balloon enteroscopy and spiral enteroscopy. J Gastroenterol Hepatol 28: 992-998, 2013.

The Internal Medicine is an Open Access article distributed under the Creative Commons Attribution-NonCommercial-NoDerivatives 4.0 International License. To view the details of this license, please visit (https://creativecommons.org/licenses/ by-nc-nd/4.0/).

(C) 2018 The Japanese Society of Internal Medicine

Intern Med 57: 1209-1212, 2018 